\title{
Correction to: The Role of Social Isolation in the Relationships Between Psychosis and Suicidal Ideation
}

\author{
Lindsay A. Bornheimer ${ }^{1} \cdot$ Juliann $\mathrm{Li}^{1} \cdot$ Vitalis $\mathrm{Im}^{1} \cdot$ Madeline Taylor $^{1} \cdot$ Joseph A. Himle ${ }^{1,2}$
}

Published online: 7 February 2020

○) Springer Science+Business Media, LLC, part of Springer Nature 2020

\section{Correction to: Clinical Social Work Journal https://doi.org/10.1007/s10615-019-00735-x}

The original version of the article unfortunately contained an error in corresponding author name. Author name was incorrectly published as 'Lindsay A. Borhneimer' and the corrected name is 'Lindsay A. Bornheimer'.

The original article has been corrected.

Publisher's Note Springer Nature remains neutral with regard to jurisdictional claims in published maps and institutional affiliations.

The original article can be found online at https://doi.org/10.1007/ s10615-019-00735-x.

Lindsay A. Bornheimer

bornheim@umich.edu

1 School of Social Work, University of Michigan, 1080 S.

University Ave., Ann Arbor, MI 48109, USA

2 Department of Psychiatry, University of Michigan,

Ann Arbor, MI, USA 